World Nutrition 2018;9(3):324

\title{
How John Mason Affected My Life
}

Irwin J. Shorr, MPH, MPS

December 24, 2018

I was saddened to learn of the loss of John Mason. I first met John at FAO in Rome in 1980 on my way home from Cameroon where I worked on a national nutrition survey under the direction of Dr. Derrick Jelliffe at the UCLA School of Public Health as part of a contract with the USAID Office of Nutrition when Marty Foreman was the Director. Our four-year contract at UCLA with USAID was ending and I was looking for work. Subsequently, John asked me to come to Rome to work at FAO on a series of anthropometric-based nutrition surveys as well as writing anthropometry-based nutrition survey training manuals that he spearheaded. While at FAO, I worked in several countries under John's supervision for two years on these surveys, where he pioneered some very innovative methods of analyzing data in-country. John was the first to use portable micro-computers in developing countries to input and rapidly analyze nutrition survey data (laptops were not yet in existence) with customized software, the creation of which he directed. After John left FAO, he took the position of Director of the Cornell Nutrition Surveillance Program at Cornell University, where he funded my obtaining a master's degree under his direction.

John's contribution to international nutrition was profound and undeniable - his publications on nutrition surveillance were landmark. He was innovative and creative, had boundless energy, enthusiasm and vision that were his trademarks, his personal signature on everything that he did. When faced with challenges, John never played the role of the victim as if to say "why me?" - he always moved forward with actions of "what do I do next?" He continued forward because that's the only way that he knew - John always landed on his feet and continued to produce and to push his own envelope and to push the envelopes of others in international nutrition. After leaving Cornell, John assumed the position of SCN Technical Secretary, where he had a major impact on the lives of many through his work, policy formation and publications. In his faculty position at Tulane, he continued teaching and research, where countless students and colleagues benefited from his knowledge, experience and wisdom.

John also had a unique sense of humor. While working with John at FAO in Rome, he told me a few stories of interactions with his father, where, after not seeing him for some years, his father first commented to John, "Well John, I see that your hair is lasting well." John once sent his father a telegram (long before the days of email) where it was common to insert the word "Stop" instead of a period after sentences, that read something like "Happy Birthday, Dad. Stop. Love, John. Stop" to which his father responded, "Stop what?" While working on my thesis at Cornell, John once asked me "Are you winning?" When I responded, "I think I see the light at the end of the tunnel", John remarked, "Beware of the light at the end of the tunnel - it may be the oncoming train!" John often cited the many times he worked with colleagues who were influenced by personal romance in scheduling work on nutrition surveys, when he said that he always wanted to publish an article, "The Role of Lust in Nutrition Surveys".

During my two years in Rome, I became close to John's family and his children, Alex and Simon, where we enjoyed many times together. Subsequently, with his wife, Karen and their daughter, Christina, their union was a joyful bonding.

With John's passing, we have lost a pioneer, author, teacher, colleague and friend. I am one of many who will forever be grateful for the impact John has had on my life. He is irreplaceable and will be sorely missed. 